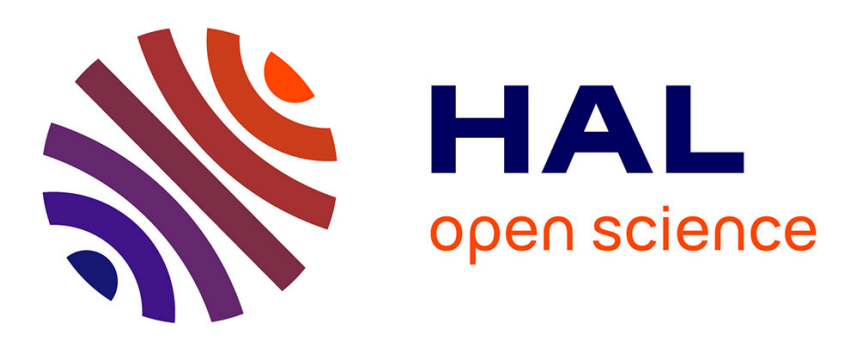

\title{
Targeted Activation of Astrocytes: A Potential Neuroprotective Strategy
}

Carole Escartin, Gilles Bonvento

\section{To cite this version:}

Carole Escartin, Gilles Bonvento. Targeted Activation of Astrocytes: A Potential Neuroprotective Strategy. Molecular Neurobiology, 2008, 38 (3), pp.231-241. 10.1007/s12035-008-8043-y . cea02168441

\section{HAL Id: cea-02168441 https://hal-cea.archives-ouvertes.fr/cea-02168441}

Submitted on 28 Jun 2019

HAL is a multi-disciplinary open access archive for the deposit and dissemination of scientific research documents, whether they are published or not. The documents may come from teaching and research institutions in France or abroad, or from public or private research centers.
L'archive ouverte pluridisciplinaire HAL, est destinée au dépôt et à la diffusion de documents scientifiques de niveau recherche, publiés ou non, émanant des établissements d'enseignement et de recherche français ou étrangers, des laboratoires publics ou privés. 


\title{
Targeted Activation of Astrocytes: A Potential Neuroprotective Strategy
}

\author{
Carole Escartin • Gilles Bonvento
}

Received: 20 June 2008 / Accepted: 26 September 2008 / Published online: 18 November 2008

(C) Humana Press Inc. 2008

\begin{abstract}
Astrocytes are involved in many key physiological processes in the brain, including glutamatergic transmission, energy metabolism, and blood flow control. They become reactive in response to pathological situations, a response that involves well-described morphological alterations and less characterized functional changes. The functional consequences of astrocyte reactivity seem to depend on the molecular pathway involved and may result in the enhancement of several neuroprotective and neurotrophic functions. We propose that a selective and controlled activation of astrocytes may switch these highly pleiotropic cells into therapeutic agents to promote neuron survival and recovery. This may represent a potent therapeutic strategy for many brain diseases in which neurons would benefit from an increased support from activated astrocytes.
\end{abstract}

Keywords Reactive astrocytes - Activation of astrocytes · Brain diseases $\cdot$ Therapeutic target $\cdot$ Cytokines
Abbreviations
AD Alzheimer's disease
ALS Amyotrophic lateral sclerosis
BrdU Bromodeoxyuridine
CNTF Ciliary neurotrophic factor
COX2 Cyclooxygenase 2

\author{
C. Escartin $(\triangle) \cdot G$. Bonvento \\ CEA, IB2M, MIRCen, CNRS URA2210, \\ 4, place du General Leclerc, \\ 91401 Orsay, France \\ e-mail: carolescartin@yahoo.fr \\ C. Escartin \\ Department of Neurology, UCSF and VA Medical Center, \\ San Francisco, CA, USA
}

$\begin{array}{ll}\text { GFAP } & \text { Glial fibrillary acidic protein } \\ \text { FGF } & \text { Fibroblast growth factor } \\ \text { KO } & \text { Knockout } \\ \text { HD } & \text { Huntington's disease } \\ \text { IGF-1 } & \text { Insulin-like growth factor 1 } \\ \text { IL } & \text { Interleukin } \\ \text { iNOS } & \text { Inducible nitric oxide synthase } \\ \text { LPS } & \text { Lipopolysaccharide } \\ \text { MCAO } & \text { Middle cerebral artery occlusion } \\ \text { MRI } & \text { Magnetic resonance imaging } \\ \text { NGF } & \text { Nerve growth factor } \\ \text { NF } \text { B } & \text { Nuclear factor-k B } \\ \text { NMDA } & \text { N-Methyl-D-aspartate } \\ \text { PET } & \text { Positron emission tomography } \\ \text { STAT3 } & \text { Signal transducer and activator of transcription } 3 \\ \text { SOCS3 } & \text { Suppressor of cytokine signaling } 3 \\ \text { SOD } & \text { Superoxide dismutase } \\ \text { SCI } & \text { Spinal cord injury } \\ \text { TGF } \beta & \text { Transforming growth factor } \beta \\ \text { TNF } \alpha & \text { Tumor necrosis factor } \alpha\end{array}$

\section{Astrocytes and Brain Diseases}

Over the last 20 years, a new field of research has emerged focusing on astrocytes, the most abundant glial cell type in the brain. Extensive study has led to many surprising discoveries regarding the role of these cells and their importance for brain function. Some of the functions of astrocytes were first proposed by Ramon y Cajal, more than a century ago, when he described the unique anatomical properties of these cells [1]. Astrocytes-with their endfeet extending toward blood vessels on one side and enclosing synapses on the other-are ideally situated to control 
metabolic supply, blood flow, ionic homeostasis, and neurotransmitter levels [2]. More recently, studies have suggested that in addition to their supportive role toward neurons, astrocytes play an active role in neuronal transmission and synaptic plasticity [3].

It is now thought that astrocytes are organized into nonoverlapping spatial domains [4-6]. In the rodent brain, a single astrocyte domain may encompass more than 100,000 synapses that may be regulated in a coordinated fashion by gliotransmitters released from this cell $[5,6]$. Another key anatomical feature of astrocytes is their interconnection by gap junctions (two apposed hemichannels of connexins) that forms a syncytium facilitating transfer of information and metabolites over distance [7]. Because of these peculiar anatomical properties, any alteration in astrocyte function is susceptible to have profound consequences for neuronal activity [3].

Astrocytes have recently been shown to play a causal or exacerbating role in several brain diseases previously thought to be purely neuronal in origin, including status epilepticus, schizophrenia, amyotrophic lateral sclerosis (ALS), and Huntington's disease (HD; for comprehensive reviews, see $[3,8,9])$. For example, mutant huntingtin, the protein responsible for $\mathrm{HD}$, is expressed in the astrocytes of patients and has been shown to reduce glutamate uptake by cultured astrocytes [10]. The mutant form of superoxide dismutase 1 (SOD1) produced in the astrocytes of some familial ALS patients is toxic to primary and embryonic stem-cell-derived motor neurons [11]. Conversely, selective invalidation of the gene encoding the mutant SOD1 in astrocytes slows disease progression [12]. It has also been suggested that the amyloid deposits observed in Alzheimer's disease (AD) may result from the dysfunctional degradation of amyloid fibrils by astrocytes [13]. Therefore, astrocyte dysfunction may play an unsuspected role in the occurrence and exacerbation of many diseases. These cells may therefore be a promising new therapeutic target for many of these pathological conditions, particularly given the unique ability of astrocytes to become reactive, which may be accompanied by marked functional alterations of potential benefit to damaged neurons.

This review will address the following issues: What are the main morphological and functional features of reactive astrocytes? Are these features unique and universal or dependent on the stimulus involved? Do reactive astrocytes promote, exacerbate, or combat pathogenic processes? Could novel therapeutic strategies for brain diseases be based on a targeted activation of astrocytes?

In the following paragraphs, we will use the term "reactive astrocytes" or "astrogliosis" as a state of astrocytes that is induced by any pathological situation by means of endogenous mechanisms, while "activated astrocytes" will refer to a state that is induced experimentally by pharmacological or genetic manipulations.

\section{General Features of Reactive Astrocytes}

Astrocyte reactivity is a general term encompassing changes in both the morphology and function of astrocytes in response to any pathological condition. The pathological stimulus may be an acute injury, such as mechanical lesions of brain parenchyma, brain trauma, ischemia, infection, or a chronic deleterious situation such as neurodegenerative diseases or aging [14-16]. Astrocyte reactivity is generally associated with microglial reactivity and, in some cases, leukocyte recruitment. Microglia, the resident immune cells of the brain, may in fact be responsible for the subsequent activation of astrocytes and may coordinate complex processes of neuroinflammation [17]. This review will focus on astrocyte activation and will not specifically address the potential dual effects of reactive microglia and immune cell infiltration for neuronal survival and brain recovery. Several comprehensive reviews have already been published on this interesting topic [18-20].

The reactive state of astrocytes was initially defined on the basis of morphological criteria. Reactive astrocytes have both hypertrophic processes and soma and overexpress intermediate filaments (glial fibrillary acidic protein (GFAP), vimentin, and nestin [21, 22]; see Fig. 1). This definition was recently refined by studies using dye-filling [23] or diolistic labeling [24] of reactive astrocytes and three-dimensional reconstruction of confocal images. Reactive astrocytes appear to have thicker main processes than resting astrocytes, without any significant alteration in their overall domain volume [23]. Their processes also tend to overlap more at the domain boundaries after epileptic seizures, but not during chronic neurodegenerative diseases [24].

After a local disruption of the brain parenchyma, reactive astrocytes extend their processes in a single plane forming a glial scar that demarcates the lesioned area from healthy parenchyma. This type of astrocyte reactivity, called anisomorphic gliosis, is irreversible [16]. By contrast, with less focal injuries such as chemical lesions or during chronic diseases, reactive astrocytes are more evenly distributed and have randomly orientated processes, a reversible phenomenon called isomorphic gliosis. Thus, even if reactive astrocytes display common features (hypertrophy and upregulation of intermediate filaments), other characteristics may depend on the stimulus involved (see below).

The classic definition of astrocyte reactivity involves cellular proliferation; however, the intensity of astrocyte proliferation appears quite variable depending on the model studied and the techniques used. Early reports using bromodeoxyuridine (BrdU) labeling or radioactive thymidine incorporation suggested that limited astrocyte proliferation occurred after brain injury (less than $5 \%$ of total 
Fig. 1 CNTF-activated astrocytes in the mouse hippocampus. Mice were injected into the hippocampus with a lentiviral vector containing the cDNA for the cytokine CNTF (CNTF) or the cDNA for $\beta$-galactosidase (Control). Two months later, astrocytes were stained for GFAP. Activated astrocytes display classical hypertrophied GFAP-positive processes. Scale bar $=20 \mu \mathrm{m}(\mathbf{a}, \mathbf{c})$ and $10 \mu \mathrm{m}(\mathbf{b}$, d). Unpublished data from $\mathrm{G}$. Bonvento and C.W. Shuttleworth
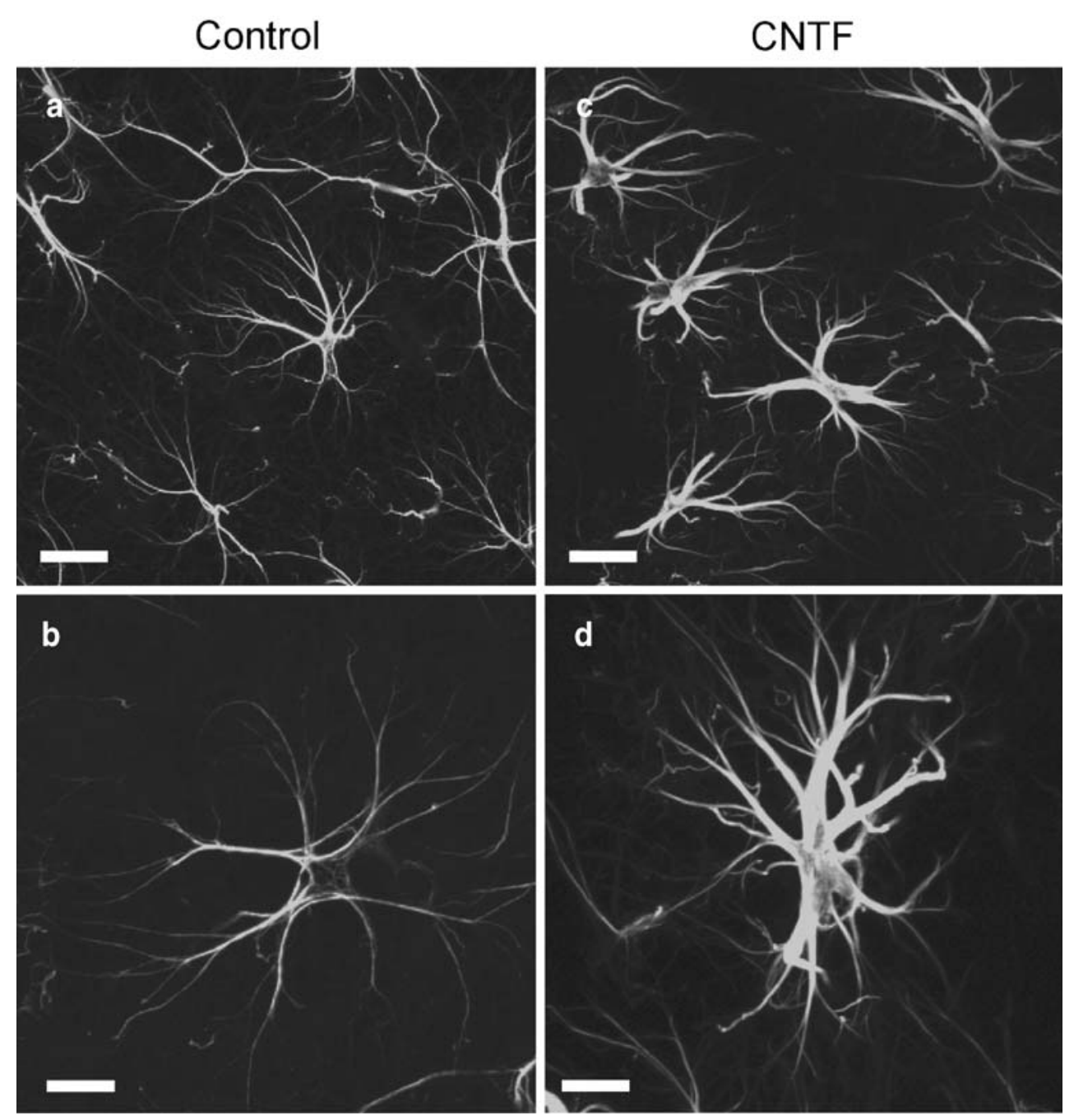

reactive astrocytes) and that the apparent increase in the number of astrocytes in pathological conditions might be linked to the production of larger amounts of GFAP (see references in [16]). However, a recent study based on genetic mapping with inducible Cre-mediated recombination in reactive astrocytes and lentivirus-tagging suggested that adult astrocytes are a significant source of proliferating, reactive astrocytes in response to stab wound injury in mice [25]. They found that up to $40 \%$ of tagged adult astrocytes incorporated BrdU after injury. The use of this elegant technique in other models of astrogliosis should provide a more general assessment of the degree of proliferation.

More functional markers of astrocyte reactivity include an increase in the levels of certain cytokines, such as interleukin-6 (IL-6) and ciliary neurotrophic factor (CNTF), adhesion/recognition molecules, as well as other proteins generally associated with detrimental effects such as calcium-binding protein $\mathrm{S} 100 \beta$, inducible NO synthase (iNOS), and cyclooxygenase 2 (COX2; reviewed in [14, 15]). Following acute injuries, astrocytes express immediate early genes such as $c$-fos and heat shock protein genes [15]. They then overexpress intermediate filaments and undergo morphological changes within a few hours [16]. In the case of isomorphic gliosis, the overexpression of some of these proteins is transient and disappears after several weeks (see references in [16]). The time course of astrocyte reactivity is quite complex and depends on the type of injury; the sequence of events being even less clear in chronic pathological states such as neurodegenerative diseases [26]. The reader is referred to several comprehensive reviews that describe the molecular profile and time course of astrocyte reactivity in different pathological conditions such as ischemia [27, 28], traumatic brain injury [29], mechanical lesions [30], or neurodegenerative diseases [18, 31].

In conclusion, while the morphological alterations of reactive astrocytes are universal and quite easily detected, functional changes appear much more subtle and depend on the stimulus involved. This complex picture has contributed to the difficulty in evaluating the functional role of reactive astrocytes in pathological conditions. 


\section{Reactive Astrocytes: Deleterious or Protective?}

Astrocytes are involved in many important brain functions. It is therefore of key importance to evaluate whether these functions are enhanced, lost, or unchanged when astrocytes are in a reactive state. This dictates whether manipulation of astrocyte reactivity is a viable therapeutic strategy for improving neuronal survival and restoring neuronal function. Two main approaches have been used to answer this question: prevention of endogenous astrocyte reactivity and activation of astrocytes by pharmacological or genetic manipulation.

Assessing the Role of Endogenous Reactive Astrocytes

One approach to interfere with astrocyte reactivity (or at least to disrupt the glial scar) involves the knockout (KO) of intermediate filament genes (encoding GFAP and/or vimentin; Table 1). Knockout mice showed no developmental or breeding abnormalities (see references in [21]). However, GFAP and vimentin double-KO mice displayed lower levels of astroglial reactivity (as seen with $\mathrm{S} 100 \beta$ and nestin immunolabeling) and greater sprouting of supraspinal axons compared with control mice, 3 days, 1 and 5 weeks after spinal cord hemisection. These features were associated with locomotor functional recovery 2 to 4 weeks following injury [32]. A similar improvement in axonal regeneration was observed in the hippocampus of double-
KO mice 2 weeks after transection of the entorhinal cortex axons [33]. Kinouchi et al. showed that astrocytes from these double-KO mice were more permissive for stem cell migration and neurite extension after retinal transplantation [34]. However, at earlier time points after entorhinal axon transection (4 days), double-KO mice displayed a lower number of synapses [33]. Indeed, a more recent study on these mice has demonstrated that reactive astrocytes may rather be beneficial for neuronal survival. Li et al. found that exposing GFAP/vimentin double-KO mice to middle cerebral artery occlusion (MCAO) resulted in an infarct size three times larger than in littermate controls or single-KO mice [36]. This increase in infarct size was accompanied by a decrease in uptake of the excitotoxic neurotransmitter glutamate and levels of plasminogen activator inhibitor 1 , a key protective protein in ischemia [36].

Other studies have used elaborate genetic tools to more directly address the role of reactive astrocytes. Sofroniew et al. developed a transgenic mouse expressing the herpes simplex virus type 1-thymidine kinase "suicide gene" under control of the mouse GFAP promoter (Table 1). The enzyme encoded by this gene phosphorylates gangiclovir, preventing further elongation of the newly synthesized DNA and triggering the death of dividing cells. This results in the specific ablation of reactive astrocytes that have strong GFAP promoter activity and are undergoing proliferation. Sofroniew et al. used this model to investigate the role of reactive, dividing astrocytes

Table 1 Main genetic approaches to investigate the role of reactive astrocytes in vivo

\begin{tabular}{|c|c|c|c|c|c|}
\hline Genetic construct & Effect & $\begin{array}{l}\text { Model of } \\
\text { astrogliosis Injury }\end{array}$ & Main outcomes & & Reference \\
\hline \multirow[t]{5}{*}{ GFAP-vimentin $\mathrm{KO}$} & \multirow[t]{5}{*}{$\begin{array}{l}\text { Disruption of cytoskeleton } \\
\text { in reactive astrocytes }\end{array}$} & $\begin{array}{l}\text { Spinal cord } \\
\text { hemisection }\end{array}$ & Increased axonal sprouting functional recovery & - & {$[32]$} \\
\hline & & $\begin{array}{l}\text { Entorhinal cortex } \\
\text { axon transection }\end{array}$ & $\begin{array}{l}\text { Improved axonal regeneration at } 2 \text { weeks } \\
\text { Decrease in synapse number at } 4 \text { days }\end{array}$ & $+/-$ & {$[33]$} \\
\hline & & $\begin{array}{l}\text { Cell transplant in } \\
\text { the retina }\end{array}$ & $\begin{array}{l}\text { Increased stem cell migration and neurite } \\
\text { extension }\end{array}$ & - & [34] \\
\hline & & Retinal detachment & Improved photoreceptor survival & - & {$[35]$} \\
\hline & & MCAO & Increase in infarct size & + & {$[36]$} \\
\hline \multirow[t]{3}{*}{$\begin{array}{l}\text { PromGFAP-TK } \\
\text { (+oral ganciclovir) }\end{array}$} & \multirow[t]{3}{*}{$\begin{array}{l}\text { Ablation of dividing } \\
\text { reactive astrocytes }\end{array}$} & $\begin{array}{l}\text { Forebrain stab } \\
\text { wound }\end{array}$ & $\begin{array}{l}\text { Increase in neurite outgrowth lesion } \\
\text { exacerbated }\end{array}$ & $+/-$ & {$[37]$} \\
\hline & & Spinal cord injury & Lesion and motor symptoms exacerbated & + & {$[38]$} \\
\hline & & $\begin{array}{l}\text { Traumatic cortical } \\
\text { injury }\end{array}$ & $\begin{array}{l}\text { Lesion exacerbated when mild injury, no effect } \\
\text { on severe injury }\end{array}$ & + & {$[39]$} \\
\hline $\begin{array}{l}\text { PromNestin-Cre X } \\
\text { STAT3 }^{\text {loxP }}\end{array}$ & $\begin{array}{l}\text { Inhibition of astrocyte } \\
\text { reactivity }\end{array}$ & Spinal cord injury & Lesion aggravated and more severe symptoms & + & {$[40]$} \\
\hline $\begin{array}{l}\text { PromNestin-Cre X } \\
\text { SOCS3 } 3^{\text {loxP }}\end{array}$ & $\begin{array}{l}\text { Enhancement of astrocyte } \\
\text { reactivity }\end{array}$ & Spinal cord injury & $\begin{array}{l}\text { Reduced lesion and improved motor } \\
\text { symptoms }\end{array}$ & + & {$[40]$} \\
\hline
\end{tabular}

This table reports only the main studies on the functional role of reactive astrocytes in vivo that are based on genetic targeting of astrocytes through the use of cell type-specific promoters. Many other studies with a nonselective KO or overexpression (of cytokines for example) have been carried out but are not mentioned here. See [41] for review on the outcomes of such experiments. Signs "+", "-", and "+/-" refer, respectively, to beneficial, detrimental, or mixed effects of reactive astrocytes on the injury outcome Prom promoter 
in various acute pathological conditions, including forebrain stab wound [37], traumatic cortical brain injury [39], and stab or crush spinal cord injury (SCI) [38]. The absence of dividing reactive astrocytes limited glial scar formation, allowing greater neurite outgrowth in the forebrain stab wound model [37]. However, the ablation of reactive astrocytes greatly increased the severity of all these lesions: Blood brain barrier repair was impaired, immune cell infiltration levels were higher, and neuronal death was significantly enhanced. In the forebrain stab wound model, memantine (a $N$-methyl-D-aspartate (NMDA) glutamate receptor antagonist) partially prevented neuronal death in the CA1 region of the hippocampus of reactive astrocyteablated mice [37], highlighting the key role of reactive astrocytes in promoting glutamate homeostasis. In the SCI model, significant levels of oligodendrocyte death accompanied by severe demyelination were also observed in reactive astrocyte-ablated mice, together with less favorable motor outcomes [38]. Myer et al. used controlled cortical impacts of different intensities to produce either moderate or severe cortical lesions leading to $18 \%$ and $88 \%$ loss of cortical tissue, respectively, and found that the ablation of dividing reactive astrocytes affected only moderate injuries [39]. This last observation suggests that the capacity of reactive astrocytes to promote brain recovery is limited, and therefore, stimulating this endogenous response to brain insult may constitute an efficient therapeutic strategy.

Okada and colleagues provided more direct evidence for beneficial roles of reactive astrocytes and for the aggravating effects of preventing astrocyte reactivity in the SCI model (Table 1). They used a conditional KO of signal transducer and activator of transcription 3 (STAT3) or suppressor of cytokine signaling 3 (SOCS3) based on the Cre-mediated recombination of these genes in reactive astrocytes [40]. STAT3 is part of the intracellular signaling pathway of many cytokines (see "Strategies to Promote a Neuroprotective Phenotype in Activated Astrocytes") and seems to be involved in astrocyte reactivity. SOCS3 is induced by STAT3 and prevents STAT3 activation, providing a negative feedback on this pathway [42]. Okada et al. showed that impairing astrocyte reactivity by invalidating STAT3 reduced the migration of reactive astrocytes toward the site of injury, increased demyelination and neuronal disruption, and worsened clinical outcomes. Invalidating SOCS3 improved all these outcomes, providing another proof-of-principle that the endogenous astrocyte response may be insufficient and that its stimulation may be beneficial [40].

Characterizing the Function of Experimentally Activated Astrocytes

The role of reactive astrocytes can also be investigated by selectively activating astrocytes independently of any pathological processes and assessing their functional properties. This approach is based on the overexpression of known inducers of astrocyte reactivity (see "Strategies to Promote a Neuroprotective Phenotype in Activated Astrocytes"), and the goal is to specifically target astrocytes, leaving other cell types as unaffected as possible. We found that astrocytes could be activated selectively in vivo through lentiviral gene transfer of the cytokine CNTF or in vitro by exposing primary mixed cultures to recombinant CNTF $[43,44]$. CNTF synthesis and release by infected cells of the striatum (mainly neurons) induced robust and stable activation of astrocytes that displayed classic features of reactive astrocytes (hypertrophy, overexpression of intermediate filaments) (see Fig. 1) [43]. On the contrary, the number of CD11b- and ED1-positive microglia/macrophages, the expression of several neuronal markers, and the spontaneous glutamatergic activity of striatal neurons remained unaffected by CNTF [43]. CNTF-activated astrocytes displayed significant alterations in two key brain functions: glutamate homeostasis and regulation of energy metabolism. CNTF-activated astrocytes expressed the glutamate transporters excitatory amino acid transporter 1 and 2 (EAAT1 and EAAT 2) with two previously undescribed posttranscriptional modifications (hyperglycosylation and recruitment to functional raft domains at the membrane), and these features were associated with significant improvements in glutamate handling in vivo [43]. CNTFactivated astrocytes also expressed a new set of metabolic enzymes and transporters involved in the ketone body pathway and fatty acid $\beta$-oxidation and displayed a higher rate of oxidation of these alternative energy substrates to glucose [44]. This metabolic plasticity increased the resistance of $\mathrm{CNTF}$-activated astrocytes to metabolic injuries (glycolysis inhibition and prolonged exposure to palmitate) and eventually improved neuronal survival in vitro [44]. A recent study of primary cultures of mouse astrocytes also reported that astrocyte activation by cytokines (IL-1 $\beta$ and/or tumor necrosis factor $\alpha$ (TNF $\alpha)$ ) altered the metabolic profile of these cells (enhanced glycolysis, pentose phosphate pathway and Krebs cycle activities and lower intracellular glycogen levels [45]). These cytokines induced additive metabolic changes (i.e., enhancement of glycolysis and decreased glycogen levels) when used in combination [45]. However, the increase in activity of the pentose phosphate pathway and the decreased metabolic response to glutamate were only observed in presence of the two cytokines. This is another demonstration that the signaling pathways responsible for astrocyte activation determine the functional outcome.

More direct neuroprotective effects of activated astrocytes have also been reported. Using CNTF or IL-1 $\beta$ to activate spinal cord astrocytes, Albrecht et al. showed enhanced production of fibroblast growth factor 2 (FGF-2) 
by CNTF-activated astrocytes, which was associated with greater survival and neurite outgrowth of cocultured motor neurons [46]. Similarly, FGF-1-activated astrocytes overexpress antioxidant enzymes and release larger amounts of nerve growth factor (NGF) [47]. Damaged neurons express the proapoptotic p75 form of the NGF receptor and are eliminated by this release of NGF, whereas "healthy" neurons may benefit from this enhanced trophic support [47]. Activation of astrocytes by both IL-1 $\beta$ and TNF $\alpha$ in vitro also results in significant increases in release of glutathione [45], which is then available to neurons for their own antioxidant defense [48].
Thus, reactive astrocytes and experimentally activated astrocytes display marked functional changes, which may either induce direct neurotrophic effects (increased release of neurotrophic factors, enhanced energetic supply, etc.) or trigger more subtle, indirect changes leading to a general improvement in brain cell function (enhanced glutamate uptake, reorganization of metabolic pathways, modulation of synaptic transmission etc., Fig. 2) [62, 63]. Even the glial scar that hinders axonal regrowth has some beneficial consequences for the brain, demarcating the injured area and preventing propagation of damage. Astrocyte reactivity appears then to be a potent endogenous defense mechanism

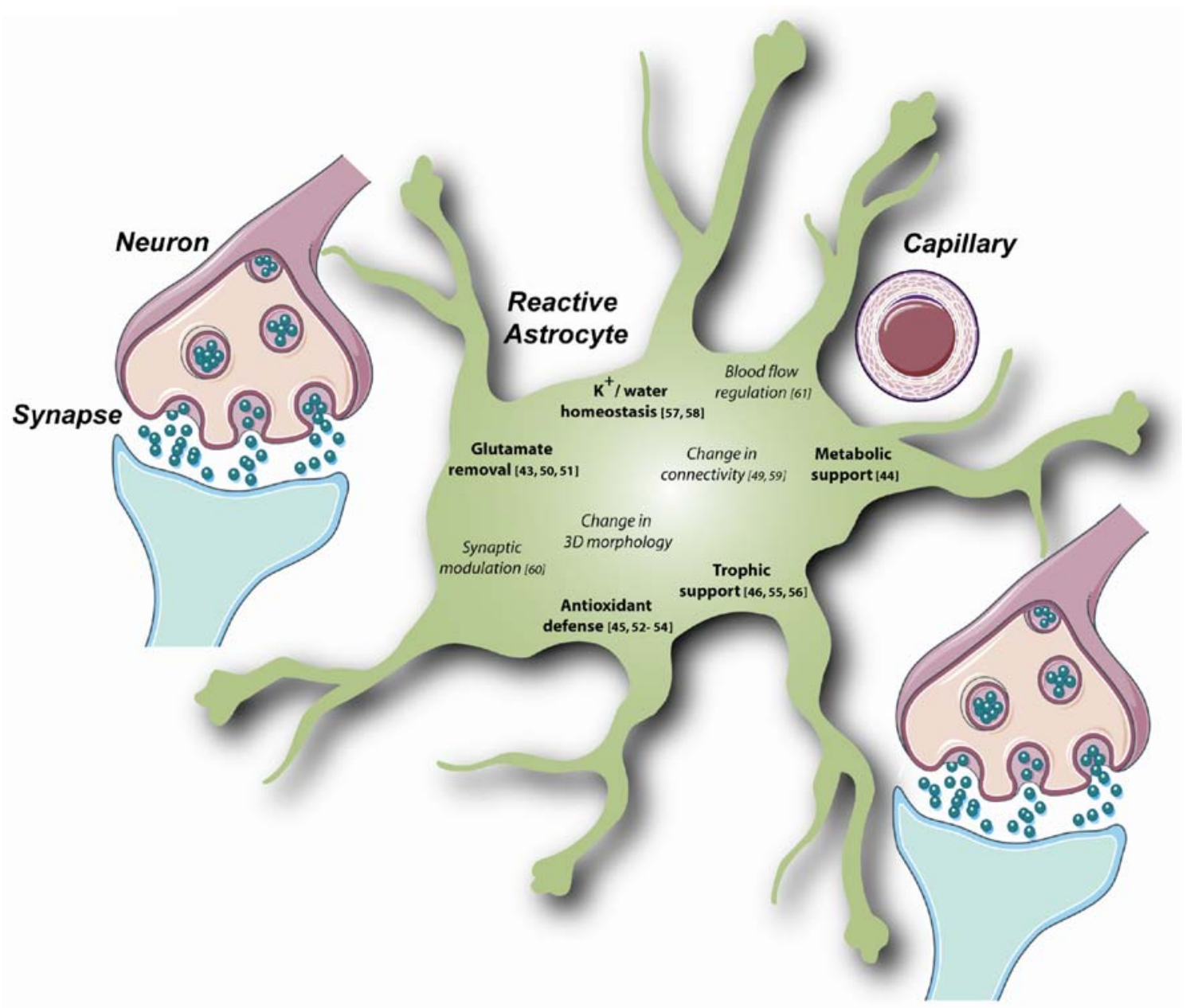

Fig. 2 Several beneficial functions may be enhanced in reactive or experimentally activated astrocytes. Activation of astrocytes by pharmacological agents or induction of astrocyte reactivity in pathological conditions may enhance the regular functions of astrocytes. Many of them involve subtle interactions with neurons and control their survival and correct function. Some of these functional changes are interrelated. For example, changes in astrocyte connectivity may have various effects on metabolite supply, synaptic transmission, and glutamate uptake, because metabolites such as glucose and neurotransmitters can pass through gap junctions [49]. Similarly, changes in the three-dimensional morphology of astrocytes may modify synapse coverage and thus, neurotransmitter removal and synapse modulation [3], Finally, changes in blood flow directly affect nutrient availability and metabolite supply. Numbers refer to key reviews or articles reporting an improvement in astrocyte function (in bold) following the experimental activation of astrocytes in vitro or in vivo (glutamate removal [43, 50, 51]; metabolic support [44]; antioxidant defense [45, 52-54]; trophic support [46, 55, 56]; $K^{+}$/ water homeostasis [57, 58]). For some more complex functions (italics), the outcome of activation is still unclear (change in connectivity [49, 59]; synaptic modulation [60]; blood flow regulation [61]). The background image was supplied by Servier Medical Art 
that could be manipulated to promote neuronal survival and recovery [20].

\section{Strategies to Promote a Neuroprotective Phenotype in Activated Astrocytes}

In order to be a valid therapeutic approach, the activation of astrocytes needs to be selective and controlled. Astrocyte activation is associated with many different functional outcomes that may have variable degrees of effectiveness on neuronal survival. It is thus necessary to characterize precisely the molecular cascades resulting in these different activation states. Cytokines are key inducers of astrogliosis (see above) [26, 64]; they activate various intracellular pathways, including the p38/MAPK pathway [65], the Janus kinase/STAT pathway [40], and the nuclear factor- $K$ $\mathrm{B}(\mathrm{NF \kappa B})$ pathway [66], all of which are potential targets for promoting tight control of activation state. Some cytokines are typically described as detrimental, inducing excessive inflammatory processes and cell death in the brain, while others, used at an appropriate concentration, may have more physiological and even neuroprotective effects $[17,67,68]$.

One way to make activated astrocytes beneficial would be to modulate their cytokine "repertoire" by favoring the production of beneficial cytokines.

Munoz et al. showed that a specific inhibitor of p38/ MAPK decreases the production of two proinflammatory cytokines (IL-1 $\beta$ and TNF $\alpha$ ) and improves behavioral outcomes following amyloid $\beta$ injection into the mouse hippocampus [69]. However, the functional changes induced by this treatment remain unclear. Brambrilla and colleagues have developed a transgenic mouse overexpressing a dominant form of the NFKB inhibitor I $\mathrm{KB}$ under the GFAP promoter [70]. These mice showed no obvious motor or behavioral deficits, no gross anatomical alterations, or neuronal cell loss in the spinal cord [70]. The nearly complete abrogation of NFkB activation in astrocytes following contusive SCI did not prevent the appearance of GFAP-positive astrocytes after 8 weeks nor did it change the production of some proinflammatory cytokines (TNF $\alpha$, RANTES) after 1 day. However, it decreased the injuryinduced production of other cytokines/chemokines (transforming growth factor $\beta 2$ (TGF $\beta 2$ ), MCP-1, and CXCL10) while increasing the release of IL-6. This change in the pattern of cytokine production was associated with a greater sparing of white matter tracks and better functional recovery 8 weeks after SCI [70]. This study confirms that the NFKB pathway is a potential target for modulating the cytokine repertoire and astrocyte activation. However, $\mathrm{NF} \kappa \mathrm{B}$ is a key transcription factor controlling many other prosurvival and neurotrophic genes [66], and it may be more efficient to regulate astrocyte activation with a more selective target. The insulin-like growth factor (IGF-1)calcineurin pathway has recently been identified as a potential pathway controlling the switch between the proand antineuroprotective properties of reactive astrocytes [71]. In situ, calcineurin is expressed by reactive astrocytes surrounding amyloid plaques in a transgenic mouse model of $\mathrm{AD}$ and in the hippocampus of aged mice [72]. The overexpression of a constitutively active form of calcineurin through adenoviral gene transfer in hippocampal neuron-astrocyte cultures activates astrocytes, which display cellular hypertrophy and express several "classic" genes of reactive astrocytes $(\mathrm{S} 100 \beta$, vimentin, antioxidant enzymes...), as seen with microarray analysis [72]. Conversely, in vitro calcineurin gene knockdown decreases the production of iNOS and COX2 by reactive astrocytes after exposure to lipopolysaccharide (LPS) [71]. But intriguingly, the overexpression of a constitutive form of calcineurin in astrocytes reduces their production of deleterious molecules such as COX2, iNOS, and proinflammatory cytokines after exposure to TNF $\alpha$ or LPS in vitro and in response to penetrating cortical injury or LPS injection in vivo [71]. This suggests that calcineurin does not simply activate astrocytes but rather modulates their phenotype. Indeed, the authors made the interesting observation that in rat cultured astrocytes, a delayed activation of calcineurin by IGF-1, 3 or $16 \mathrm{~h}$ after treatment with TNF $\alpha$ or LPS respectively, could counteract their deleterious effects on neuronal survival and astrocyte ROS production. Therefore, the authors propose that a primary activation of calcineurin by proinflammatory stimuli such as TNF $\alpha$ or LPS triggers deleterious proinflammatory cascades and that a secondary or sustained activation of astrocyte (by IGF-1 or by genetic manipulation) modulates astrocyte reactivity, shifting them toward a more protective phenotype [71].

There are some successful reports of neuroprotection using cytokines known to activate astrocytes in relevant in vivo models of brain diseases. Lentiviral gene transfer of IL-6 in the rat striatum activates astrocytes (as seen with their increased GFAP expression after 2 weeks) and protects neurons against excitotoxic lesions [73]. Intracerebroventricular injections of recombinant IL-6 significantly decreased infarct size when injected $30 \mathrm{~min}$ before and $15 \mathrm{~min}$ after MCAO [74]. In mouse, 1-h pre-injection of recombinant TGF $\beta 1$ or 1-week pre-infection with an adenovirus encoding for the TGF $\beta 1$ gene protects CA3 mouse hippocampal neurons against kainate toxicity [75]. In several primate models of HD, CNTF treatment has been shown to be neuroprotective $[76,77]$. In particular, in the progressive model of striatal degeneration induced by the mitochondrial toxin 3-nitropropionic acid, implantation of capsules of cells genetically modified to secrete CNTF at the onset of symptoms results in a significant protection of 
striatal and cortical neurons and reversal of existing motor and cognitive deficits [76]. Thus, even a delayed activation of astrocytes is effective, suggesting that the targeted activation of astrocytes may be a valid therapeutic strategy for ongoing diseases in which astrocytes may already be reactive.

However, these experiments only provide a necessary proof-of-principle that activation of astrocytes can be associated with neuroprotective effects. The demonstration that cytokine-activated astrocytes really mediate these protective effects is still lacking. Transgenic mice, in which astrocyte reactivity can be prevented, such as the conditional STAT3 KO mice [40], may allow to test this hypothesis.

\section{New Molecular Tools to Target and Monitor Activated Astrocytes}

Advances in molecular biology and gene transfer technologies have made it possible to target astrocytes more specifically and thus both to address long-standing questions regarding the role of reactive astrocytes and to use these cells as therapeutic agents.

Conditional KO mice that express genes selectively in astrocytes or even in reactive astrocytes are now available. The expression of the Cre recombinase gene is placed under the control of an astrocyte-specific promoter (such as the GLAST, connexin 30, aquaporin 4, or apolipoprotein E promoters) [78] or a reactive astrocyte-specific promoter (nestin) [40]. In addition, the activity of a modified form of the recombinase $\left(\mathrm{CreER}^{\mathrm{T} 2}\right)$ can be controlled by tamoxifen injections [79], facilitating the temporal control of the KO process in reactive astrocytes. These are powerful models to investigate the involvement of specific proteins in astrocyte reactivity.

Viral vectors are useful alternative tools, and recently, we developed lentiviral vectors, which result in high levels of transgene expression in astrocytes, while transgene expression is repressed in neurons (Colin et al., submitted). These vectors will facilitate the targeted activation of astrocytes without interfering with other cell types. Lentiviral vectors are very versatile experimental tools and may carry conditional sequences to control the pattern of transgene expression over time. Further, they can be injected into spatially restricted structures in adult animals from various species $[80,81]$. They also represent a unique way of selectively delivering therapeutic molecules to brain cells while inducing minimal peripheral side effects [80, 81].

The development of potent imaging techniques, particularly for live imaging, has also opened new opportunities to investigate the role of reactive astrocytes [3]. Such techniques allow to evaluate changes in activated astrocytes at the single cell level or to quantify astrocyte activation at the brain-structure level. Specific monitoring of activated astrocytes is particularly important in the context of a cellbased therapeutic approach such as the targeted activation of astrocytes. Using two-photon imaging of astrocytes labeled with sulforhodamine 101 in the mouse cortex [82], Nimmerjahn et al. studied the response of astrocytes to "micro-stroke" and showed that these cells are much less motile than microglia [83]. Similar anatomical analyses of astrocyte activation can be performed with fluorescent reporter genes under the control of the GFAP promoter (or that of another intermediate filament gene induced in reactive astrocytes [84]). Fluorescent proteins have been used to analyze the morphological features of normal $[6$, 85] or reactive astrocytes [86] in brain slices and in vivo. To obtain more global but quantitative information on astrocyte activation, luciferase may be used as an alternative reporter gene and can be monitored and quantified by biophotonic/bioluminescence imaging [87].

Positron emission tomography (PET) is another noninvasive and quantitative imaging system, which can be used to study the whole brain simultaneously, as opposed to analysis of superficial structures performed with twophoton microscopy. PET ligands available for following neuroinflammation bind mostly to reactive microglia, but may also label reactive astrocytes to some extent [88]. The development of more selective ligands for reactive astrocytes is required to follow astrocyte activation specifically in rodents and primates, using PET in preclinical paradigms. Magnetic resonance imaging (MRI) is an additional standard brain imaging technique that can be used in rodents, primates, and humans. This technique has been recently used to follow astrocyte reactivity $2 \mathrm{~h}$ following two types of acute brain injury in rats. These studies demonstrated that both low-flow ischemia induced by endothelin-1 injection and NMDA-mediated excitotoxic injury induced a detectable MRI signal (increase in $T_{1}$ relaxation) [89]. Both PET and MRI may therefore be invaluable tools in both preclinical and clinical studies to provide noninvasive measurements of astrocyte activation over time throughout the brain.

\section{Conclusions}

Reactive astrocytes were once thought to be detrimental cells responsible for neuronal demise, but recent studies have changed this view and they are now considered as potential endogenous repair agents $[62,63,90,91]$. The intrinsic capacity of astrocytes to react to any type of brain injury and to develop a broad range of defense mechanisms makes them a very interesting therapeutic target. This is 
particularly true, because many neurological diseases share common pathological mechanisms such as oxidative stress, excitotoxicity, and metabolic impairment that are linked to functions regulated by astrocytes. The pleiotropic nature of astrocytes makes these cells ideally suited for combating multifactorial brain diseases. It is now necessary to develop better molecular tools to direct and control the status of activated astrocytes and to switch them into supportive cells for neurons exposed to various detrimental conditions.

Acknowledgment We thank Dr. Angela Brennan for her careful reading of the manuscript.

\section{References}

1. Somjen GG (1988) Nervenkitt: notes on the history of the concept of neuroglia. Glia 1:2-9

2. Ransom B, Behar T, Nedergaard M (2003) New roles for astrocytes (stars at last). Trends Neurosci 26:520-522

3. Halassa MM, Fellin T, Haydon PG (2007) The tripartite synapse: roles for gliotransmission in health and disease. Trends Mol Med 13:54-63

4. Bushong EA, Martone ME, Ellisman MH (2004) Maturation of astrocyte morphology and the establishment of astrocyte domains during postnatal hippocampal development. Int J Dev Neurosci 22:73-86

5. Bushong EA, Martone ME, Jones YZ, Ellisman MH (2002) Protoplasmic astrocytes in CA1 stratum radiatum occupy separate anatomical domains. J Neurosci 22:183-192

6. Halassa MM, Fellin T, Takano H, Dong JH, Haydon PG (2007) Synaptic islands defined by the territory of a single astrocyte. J Neurosci 27:6473-6477

7. Theis M, Sohl G, Eiberger J, Willecke K (2005) Emerging complexities in identity and function of glial connexins. Trends Neurosci 28:188-195

8. Lobsiger CS, Cleveland DW (2007) Glial cells as intrinsic components of non-cell-autonomous neurodegenerative disease. Nat Neurosci 10:1355-1360

9. Seifert G, Schilling K, Steinhauser C (2006) Astrocyte dysfunction in neurological disorders: a molecular perspective. Nat Rev Neurosci 7:194-206

10. Shin JY, Fang ZH, Yu ZX, Wang CE, Li SH, Li XJ (2005) Expression of mutant huntingtin in glial cells contributes to neuronal excitotoxicity. J Cell Biol 171:1001-1012

11. Nagai M, Re DB, Nagata T, Chalazonitis A, Jessell TM, Wichterle H, Przedborski S (2007) Astrocytes expressing ALS-linked mutated SOD1 release factors selectively toxic to motor neurons. Nat Neurosci 10:615-622

12. Yamanaka K, Chun SJ, Boillee S, Fujimori-Tonou N, Yamashita H, Gutmann DH, Takahashi R, Misawa H, Cleveland DW (2008) Astrocytes as determinants of disease progression in inherited amyotrophic lateral sclerosis. Nat Neurosci 11:251-253

13. Wyss-Coray T, Loike JD, Brionne TC, Lu E, Anankov R, Yan F, Silverstein SC, Husemann J (2003) Adult mouse astrocytes degrade amyloid-beta in vitro and in situ. Nat Med 9:453-457

14. Ridet JL, Malhotra SK, Privat A, Gage FH (1997) Reactive astrocytes: cellular and molecular cues to biological function. Trends Neurosci 20:570-577

15. Eddleston M, Mucke L (1993) Molecular profile of reactive astrocytes-implications for their role in neurologic disease. Neuroscience 54:15-36
16. Kalman M (2004) Glial reaction and reactive glia. In: Non neuronal cells of the nervous system: function and dysfunction. Hertz L (ed) Elsevier, Amsterdam, pp 787-835

17. Allan SM, Rothwell NJ (2003) Inflammation in central nervous system injury. Philos Trans R Soc Lond B Biol Sci 358:16691677

18. Wyss-Coray T, Mucke L (2002) Inflammation in neurodegenerative disease - a double-edged sword. Neuron 35:419-432

19. Hohlfeld R, Kerschensteiner M, Meinl E (2007) Dual role of inflammation in CNS disease. Neurology 68:S58-S63, discussion S91-56

20. Popovich PG, Longbrake EE (2008) Can the immune system be harnessed to repair the CNS? Nat Rev Neurosci 9:481-493

21. Pekny M, Wilhelmsson U, Bogestal YR, Pekna M (2007) The role of astrocytes and complement system in neural plasticity. Int Rev Neurobiol 82:95-111

22. Pekny M, Nilsson M (2005) Astrocyte activation and reactive gliosis. Glia 50:427-434

23. Wilhelmsson U, Bushong EA, Price DL, Smarr BL, Phung V, Terada M, Ellisman MH, Pekny M (2006) Redefining the concept of reactive astrocytes as cells that remain within their unique domains upon reaction to injury. Proc Natl Acad Sci USA 103:17513-17518

24. Oberheim NA, Tian GF, Han X, Peng W, Takano T, Ransom B, Nedergaard M (2008) Loss of astrocytic domain organization in the epileptic brain. J Neurosci 28:3264-3276

25. Buffo A, Rite I, Tripathi P, Lepier A, Colak D, Horn AP, Mori T, Gotz M (2008) Origin and progeny of reactive gliosis: a source of multipotent cells in the injured brain. Proc Natl Acad Sci USA 105:3581-3586

26. Raivich G, Bohatschek M, Kloss CU, Werner A, Jones LL, Kreutzberg GW (1999) Neuroglial activation repertoire in the injured brain: graded response, molecular mechanisms and cues to physiological function. Brain Res Brain Res Rev 30:77-105

27. Swanson RA, Ying W, Kauppinen TM (2004) Astrocyte influences on ischemic neuronal death. Curr Mol Med 4:193-205

28. Trendelenburg G, Dirnagl U (2005) Neuroprotective role of astrocytes in cerebral ischemia: focus on ischemic preconditioning. Glia 50:307-320

29. Floyd CL, Lyeth BG (2007) Astroglia: important mediators of traumatic brain injury. Prog Brain Res 161:61-79

30. Silver J, Miller JH (2004) Regeneration beyond the glial scar. Nat Rev Neurosci 5:146-156

31. Minagar A, Shapshak P, Fujimura R, Ownby R, Heyes M, Eisdorfer C (2002) The role of macrophage/microglia and astrocytes in the pathogenesis of three neurologic disorders: HIV-associated dementia, Alzheimer disease, and multiple sclerosis. J Neurol Sci 202:13-23

32. Menet V, Prieto M, Privat A, Gimenez y Ribotta M (2003) Axonal plasticity and functional recovery after spinal cord injury in mice deficient in both glial fibrillary acidic protein and vimentin genes. Proc Natl Acad Sci USA 100:8999-9004

33. Wilhelmsson U, Li L, Pekna M, Berthold CH, Blom S, Eliasson C, Renner O, Bushong E, Ellisman M, Morgan TE, Pekny M (2004) Absence of glial fibrillary acidic protein and vimentin prevents hypertrophy of astrocytic processes and improves posttraumatic regeneration. J Neurosci 24:5016-5021

34. Kinouchi R, Takeda M, Yang L, Wilhelmsson U, Lundkvist A, Pekny M, Chen DF (2003) Robust neural integration from retinal transplants in mice deficient in GFAP and vimentin. Nat Neurosci 6:863-868

35. Nakazawa T, Takeda M, Lewis GP, Cho KS, Jiao J, Wilhelmsson U, Fisher SK, Pekny M, Chen DF, Miller JW (2007) Attenuated glial reactions and photoreceptor degeneration after retinal detachment in mice deficient in glial fibrillary acidic protein and vimentin. Invest Ophthalmol Vis Sci 48:2760-2768 
36. Li L, Lundkvist A, Andersson D, Wilhelmsson U, Nagai N, Pardo AC, Nodin C, Stahlberg A, Aprico K, Larsson K, Yabe T, Moons L, Fotheringham A, Davies I, Carmeliet P, Schwartz JP, Pekna M, Kubista M, Blomstrand F, Maragakis N, Nilsson M, Pekny M (2008) Protective role of reactive astrocytes in brain ischemia. J Cereb Blood Flow Metab 28(3):468-481

37. Bush TG, Puvanachandra N, Horner CH, Polito A, Ostenfeld T, Svendsen CN, Mucke L, Johnson MH, Sofroniew MV (1999) Leukocyte infiltration, neuronal degeneration, and neurite outgrowth after ablation of scar-forming, reactive astrocytes in adult transgenic mice. Neuron 23:297-308

38. Faulkner JR, Herrmann JE, Woo MJ, Tansey KE, Doan NB, Sofroniew MV (2004) Reactive astrocytes protect tissue and preserve function after spinal cord injury. J Neurosci 24:21432155

39. Myer DJ, Gurkoff GG, Lee SM, Hovda DA, Sofroniew MV (2006) Essential protective roles of reactive astrocytes in traumatic brain injury. Brain 129:2761-2772

40. Okada S, Nakamura M, Katoh H, Miyao T, Shimazaki T, Ishii K, Yamane J, Yoshimura A, Iwamoto Y, Toyama Y, Okano H (2006) Conditional ablation of Stat3 or Socs3 discloses a dual role for reactive astrocytes after spinal cord injury. Nat Med 12:829-834

41. Stoll G, Jander S, Schroeter M (2000) Cytokines in CNS disorders: neurotoxicity versus neuroprotection. J Neural Transm Suppl 59:81-89

42. Auernhammer CJ, Melmed S (2001) The central role of SOCS-3 in integrating the neuro-immunoendocrine interface. J Clin Invest 108:1735-1740

43. Escartin C, Brouillet E, Gubellini P, Trioulier Y, Jacquard C, Smadja C, Knott GW, Kerkerian-Le Goff L, Deglon N, Hantraye P, Bonvento G (2006) Ciliary neurotrophic factor activates astrocytes, redistributes their glutamate transporters GLAST and GLT-1 to raft microdomains, and improves glutamate handling in vivo. J Neurosci 26:5978-5989

44. Escartin C, Pierre K, Colin A, Brouillet E, Delzescaux T, Guillermier M, Dhenain M, Deglon N, Hantraye P, Pellerin L, Bonvento G (2007) Activation of astrocytes by CNTF induces metabolic plasticity and increases resistance to metabolic insults. J Neurosci 27:7094-7104

45. Gavillet M, Allaman I, Magistretti PJ (2008) Modulation of astrocytic metabolic phenotype by proinflammatory cytokines. Glia 56:975-989

46. Albrecht PJ, Dahl JP, Stoltzfus OK, Levenson R, Levison SW (2002) Ciliary neurotrophic factor activates spinal cord astrocytes, stimulating their production and release of fibroblast growth factor-2, to increase motor neuron survival. Exp Neurol 173:4662

47. Pehar M, Vargas MR, Cassina P, Barbeito AG, Beckman JS, Barbeito L (2005) Complexity of astrocyte-motor neuron interactions in amyotrophic lateral sclerosis. Neurodegener Dis 2:139146

48. Dringen R (2000) Metabolism and functions of glutathione in brain. Prog Neurobiol 62:649-671

49. Rouach N, Avignone E, Meme W, Koulakoff A, Venance L, Blomstrand F, Giaume C (2002) Gap junctions and connexin expression in the normal and pathological central nervous system. Biol Cell 94:457-475

50. Vermeiren C, Najimi M, Vanhoutte N, Tilleux S, de Hemptinne I, Maloteaux JM, Hermans E (2005) Acute up-regulation of glutamate uptake mediated by mGluR5a in reactive astrocytes. J Neurochem 94:405-416

51. O'Shea RD, Lau CL, Farso MC, Diwakarla S, Zagami CJ, Svendsen BB, Feeney SJ, Callaway JK, Jones NM, Pow DV, Danbolt NC, Jarrott B, Beart PM (2006) Effects of lipopolysaccharide on glial phenotype and activity of glutamate transporters: evidence for delayed up-regulation and redistribution of GLT-1. Neurochem Int 48:604-610

52. Siushansian R, Tao L, Dixon SJ, Wilson JX (1997) Cerebral astrocytes transport ascorbic acid and dehydroascorbic acid through distinct mechanisms regulated by cyclic AMP. J Neurochem 68:2378-2385

53. Lindenau J, Noack H, Asayama K, Wolf G (1998) Enhanced cellular glutathione peroxidase immunoreactivity in activated astrocytes and in microglia during excitotoxin induced neurodegeneration. Glia 24:252-256

54. Noack H, Lindenau J, Rothe F, Asayama K, Wolf G (1998) Differential expression of superoxide dismutase isoforms in neuronal and glial compartments in the course of excitotoxically mediated neurodegeneration: relation to oxidative and nitrergic stress. Glia 23:285-297

55. Nakagawa T, Yabe T, Schwartz JP (2005) Gene expression profiles of reactive astrocytes cultured from dopamine-depleted striatum. Neurobiol Dis 20:275-282

56. Rudge JS, Pasnikowski EM, Holst P, Lindsay RM (1995) Changes in neurotrophic factor expression and receptor activation following exposure of hippocampal neuron/astrocyte cocultures to kainic acid. J Neurosci 15:6856-6867

57. Perillan PR, Chen M, Potts EA, Simard JM (2002) Transforming growth factor-beta 1 regulates Kir2.3 inward rectifier $\mathrm{K}+$ channels via phospholipase $\mathrm{C}$ and protein kinase $\mathrm{C}$-delta in reactive astrocytes from adult rat brain. J Biol Chem 277:1974-1980

58. Leis JA, Bekar LK, Walz W (2005) Potassium homeostasis in the ischemic brain. Glia 50:407-416

59. Kielian T (2008) Glial connexins and gap junctions in CNS inflammation and disease. J Neurochem 106:1000-1016

60. Bezzi P, Domercq M, Brambilla L, Galli R, Schols D, De Clercq E, Vescovi A, Bagetta G, Kollias G, Meldolesi J, Volterra A (2001) CXCR4-activated astrocyte glutamate release via TNFalpha: amplification by microglia triggers neurotoxicity. Nat Neurosci 4:702-710

61. Iadecola C, Nedergaard M (2007) Glial regulation of the cerebral microvasculature. Nat Neurosci 10:1369-1376

62. Liberto CM, Albrecht PJ, Herx LM, Yong VW, Levison SW (2004) Pro-regenerative properties of cytokine-activated astrocytes. J Neurochem 89:1092-1100

63. Sofroniew MV (2005) Reactive astrocytes in neural repair and protection. Neuroscientist 11:400-407

64. John GR, Lee SC, Brosnan CF (2003) Cytokines: powerful regulators of glial cell activation. Neuroscientist 9:10-22

65. Schieven GL (2005) The biology of p38 kinase: a central role in inflammation. Curr Top Med Chem 5:921-928

66. O’Neill LA, Kaltschmidt C (1997) NF-kappa B: a crucial transcription factor for glial and neuronal cell function. Trends Neurosci 20:252-258

67. Allan SM, Rothwell NJ (2001) Cytokines and acute neurodegeneration. Nat Rev Neurosci 2:734-744

68. Lucas SM, Rothwell NJ, Gibson RM (2006) The role of inflammation in CNS injury and disease. Br J Pharmacol 147 (Suppl 1):S232-S240

69. Munoz L, Ranaivo HR, Roy SM, Hu W, Craft JM, McNamara LK, Chico LW, Van Eldik LJ, Watterson DM (2007) A novel p38 alpha MAPK inhibitor suppresses brain proinflammatory cytokine up-regulation and attenuates synaptic dysfunction and behavioral deficits in an Alzheimer's disease mouse model. J Neuroinflammation $4: 21$

70. Brambilla R, Bracchi-Ricard V, Hu WH, Frydel B, Bramwell A, Karmally S, Green EJ, Bethea JR (2005) Inhibition of astroglial nuclear factor kappaB reduces inflammation and improves functional recovery after spinal cord injury. J Exp Med 202:145-156 
71. Fernandez AM, Fernandez S, Carrero P, Garcia-Garcia M, TorresAleman I (2007) Calcineurin in reactive astrocytes plays a key role in the interplay between proinflammatory and anti-inflammatory signals. J Neurosci 27:8745-8756

72. Norris CM, Kadish I, Blalock EM, Chen KC, Thibault V, Porter NM, Landfield PW, Kraner SD (2005) Calcineurin triggers reactive/inflammatory processes in astrocytes and is upregulated in aging and Alzheimer's models. J Neurosci 25:4649-4658

73. Bensadoun JC, de Almeida LP, Dreano M, Aebischer P, Deglon N (2001) Neuroprotective effect of interleukin-6 and IL6/IL6R chimera in the quinolinic acid rat model of Huntington's syndrome. Eur J Neurosci 14:1753-1761

74. Loddick SA, Turnbull AV, Rothwell NJ (1998) Cerebral interleukin-6 is neuroprotective during permanent focal cerebral ischemia in the rat. J Cereb Blood Flow Metab 18:176-179

75. Boche D, Cunningham C, Gauldie J, Perry VH (2003) Transforming growth factor-beta 1-mediated neuroprotection against excitotoxic injury in vivo. J Cereb Blood Flow Metab 23:11741182

76. Mittoux V, Joseph JM, Conde F, Palfi S, Dautry C, Poyot T, Bloch J, Deglon N, Ouary S, Nimchinsky EA, Brouillet E, Hof PR, Peschanski M, Aebischer P, Hantraye P (2000) Restoration of cognitive and motor functions by ciliary neurotrophic factor in a primate model of Huntington's disease. Hum Gene Ther 11:11771187

77. Emerich DF, Winn SR, Hantraye PM, Peschanski M, Chen EY, Chu Y, McDermott P, Baetge EE, Kordower JH (1997) Protective effect of encapsulated cells producing neurotrophic factor CNTF in a monkey model of Huntington's disease. Nature 386:395-399

78. Slezak M, Goritz C, Niemiec A, Frisen J, Chambon P, Metzger D, Pfrieger FW (2007) Transgenic mice for conditional gene manipulation in astroglial cells. Glia 55:1565-1576

79. Mori T, Tanaka K, Buffo A, Wurst W, Kuhn R, Gotz M (2006) Inducible gene deletion in astroglia and radial glia - a valuable tool for functional and lineage analysis. Glia 54:21-34

80. Déglon N, Hantraye P (2005) Viral vectors as tools to model and treat neurodegenerative disorders. J Gene Med 7:530-539
81. Wong LF, Goodhead L, Prat C, Mitrophanous KA, Kingsman SM, Mazarakis ND (2006) Lentivirus-mediated gene transfer to the central nervous system: therapeutic and research applications. Hum Gene Ther 17:1-9

82. Nimmerjahn A, Kirchhoff F, Kerr JN, Helmchen F (2004) Sulforhodamine 101 as a specific marker of astroglia in the neocortex in vivo. Nat Methods 1:31-37

83. Nimmerjahn A, Kirchhoff F, Helmchen F (2005) Resting microglial cells are highly dynamic surveillants of brain parenchyma in vivo. Science 308:1314-1318

84. Correa-Cerro LS, Mandell JW (2007) Molecular mechanisms of astrogliosis: new approaches with mouse genetics. J Neuropathol Exp Neurol 66:169-176

85. Benediktsson AM, Schachtele SJ, Green SH, Dailey ME (2005) Ballistic labeling and dynamic imaging of astrocytes in organotypic hippocampal slice cultures. J Neurosci Methods 141:41-53

86. Shannon C, Salter M, Fern R (2007) GFP imaging of live astrocytes: regional differences in the effects of ischaemia upon astrocytes. J Anat 210:684-692

87. Cordeau P Jr, Lalancette-Hebert M, Weng YC, Kriz J (2008) Live imaging of neuroinflammation reveals sex and estrogen effects on astrocyte response to ischemic injury. Stroke 39:935-942

88. Rojas S, Martin A, Arranz MJ, Pareto D, Purroy J, Verdaguer E, Llop J, Gomez V, Gispert JD, Millan O, Chamorro A, Planas AM (2007) Imaging brain inflammation with [(11)C]PK11195 by PET and induction of the peripheral-type benzodiazepine receptor after transient focal ischemia in rats. J Cereb Blood Flow Metab 27:1975-1986

89. Sibson NR, Lowe JP, Blamire AM, Martin MJ, Obrenovitch TP, Anthony DC (2008) Acute astrocyte activation in brain detected by MRI: new insights into T(1) hypointensity. J Cereb Blood Flow Metab 28:621-632

90. Chen Y, Swanson RA (2003) Astrocytes and brain injury. J Cereb Blood Flow Metab 23:137-149

91. Dirnagl U, Simon RP, Hallenbeck JM (2003) Ischemic tolerance and endogenous neuroprotection. Trends Neurosci $26: 248-254$ 